\title{
The Effect of the Fluid Film Variable Viscosity on the Hydrostatic Thrust Spherical Bearing Performance in the Presence of Centripetal Inertia and Surface Roughness
}

\author{
Ahmad Waguih Yacout Elescandarany \\ Department of Mechanical Engineering, Faculty of Engineering, Alexandria University, Alex, Egypt \\ Email address: \\ yacouta2@asme.org

\section{To cite this article:} \\ Ahmad Waguih Yacout Elescandarany. The Effect of the Fluid Film Variable Viscosity on the Hydrostatic Thrust Spherical Bearing \\ Performance in the Presence of Centripetal Inertia and Surface Roughness. International Journal of Mechanical Engineering and \\ Applications. Vol. 6, No. 1, 2018, pp. 1-12. doi: 10.11648/j.ijmea.20180601.11
}

Received: January 9, 2018; Accepted: January 22, 2018; Published: March 7, 2018

\begin{abstract}
In response to the importance of the industry great need to the hydrostatic thrust spherical bearing, this study is performed. The stochastic modified Reynolds equation (developed by the author in his previous papers) applied to this type of bearings has become more developed to deal with the bearing static performance under the effect of the fluid film viscosity variation. The study showed the effect of the viscosity variation on the pressure, the load, the flow rate, the frictional torque, the friction factor, the power factor, the stiffness factor and the central pressure ratio as well as the effect of the speed parameter and the eccentricity on the temperature rise. The partial differential equation of the temperature gradient is derived from the fluid governing equations, integrated and applied to this type of bearings to calculate and predict the temperature distribution along the fluid film. The application of this temperature equation proved the excellence of the aforementioned optimum design of this bearing in our previous papers where the temperature of the outlet flow was less than 14 degrees centigrade over its inlet temperature.
\end{abstract}

Keywords: Hydrostatic Bearings, Spherical Bearings, Surface Roughness, Inertia Effect, Variable Viscosity Effect, Temperature Rise of the Fluid Film

\section{Introduction}

Expanding the author's previous studies on the hydrostatic thrust spherical bearing, the viscosity variation has been considered in re-developing the stochastic modified Reynolds equation "modified by Dowson and stochastically developed by the author" [1] to be thermally valid to deal with such type of bearings.

Dowson and Taylor [2,3] stated that running the bearing at high speeds considerable temperature variation along the film in $(\Theta)$ direction was observed, where it caused viscosity variation affecting the bearing performance.

Essam Salem and Farid Khalil $[4,5]$ adopted a simple form of the viscosity variation expression where it has been introduced in the pressure gradient equation and numerically solved to get the pressure and the temperature distribution. It is found that temperature rise reduces the load and the frictional torque while increases the flow rate.

Rowe and Stout [6] studied the design and the manufacturing of the hydrostatic spherical bearing. It is stated that the most critical situations encountered involve high speeds and high flow rates when a reasonable estimate of the temperature rise is obtained by assuming that all the heat is carried out in the oil whereas the in slow moving calculations this method tends to overestimate temperature rise.

Keith Brockwell et al [7] studied the temperature characteristics of a (PSJ) pivoted shoe journal bearing where it is stated that the temperature with (load between pad) reaches $100 \mathrm{C}$ at $5000 \mathrm{rpm}$ and a load of $22.24 \mathrm{KN}$ and for the same maximum temperature and load configuration the offset pivot extends the bearing speed to be just under 6500 $\mathrm{rpm}$. Generally it was found that differences between offset and center pivot bearing temperature (both maximum and $75 \%$ pad locations) increased with speed and load.

Minhui $\mathrm{He}$ et al [8] stated that the fluid film journal bearing is critical to machine's overall reliability level and concluded that the viscosity shearing generates heat in the fluid film which lead to reduce the viscosity and to increase the temperature and the power losses.

Srinivasan V. [9] studied the annular recess conical bearing considering the inertia and the viscosity variation concluding that the speed increase leads to raise the temperature and pressure. 
Shigang Wang et al [10] studied the temperature effect on the hydrostatic bearing performance in both cases of sufficient and deficient fluid film using the "Fluent 6.5 Software" to simulate the temperature field. According to the obtained results, it is concluded that the oil will affect the temperature distribution and the temperature rise.

Xibing $\mathrm{Li}$ et al [11] stated that during working the viscosity changes as the temperature increases then the bearing performance will be affected; therefore control thermal deformation hydrostatic bearing and high efficiency cooling is the prime problem to solve.

The present study could be considered as an extension to the study of reference [1] whereas the lubricant viscosity has been treated as a constant in turn it couldn't be possible to find out the bearing thermal behavior in general and to check thermally the design of such pattern of bearing presented in this reference.

This research has opened the door widely to study the behavior of this type of bearings under the lubricant variable viscosity in the presence of the centripetal inertia and the surface roughness. The un- recessed fitted type of bearings with its different configurations has been handled in this paper.

Nomenclature

$A=-\left(6 \mu q / e^{3} \pi p_{i}\right)$

$a=$ Bearing projected area $\left(\pi R^{2}\right)$.

$C=-\left(6 \mu_{i} q / \pi\right)$.

$c_{v}=$ Lubricant specific heat

$d_{i o}=$ Bearing inlet orifice diameter.

$E(f)=$ Expected value of.

$e=$ Eccentricity.

$f=$ Dimensionless friction factor.

$F=$ Friction factor.

$H=$ Dimensionless film thickness.

$h=$ Film thickness.

$h_{o}=$ Deterministic part of the film thickness $(e \cos \theta)$.

$h_{s t}=$ Random stochastic part of the film thickness.

$h_{f}=$ Power factor

$K_{\mathrm{v}}=$ Constant of viscosity variation

$K_{\mathrm{e}}=(e / R)$.

$M=$ Dimensionless frictional torque $\quad\left(m_{o} e / 2 \pi \mu \Omega R^{4}\right)$.

$m=$ Frictional torque.

$m_{o}=$ Deterministic part of the frictional torque.

$m_{s t}=$ Random stochastic part of the frictional torque.

$N=$ Shaft speed (rpm).

$P=$ Dimensionless pressure $\left(p / p_{i}\right)$.

$p=$ Mean pressure along the film thickness.

$p_{i}=$ Inlet pressure.

$p_{s}=$ Supply pressure $\left(5 \times 10^{5} \mathrm{~N} / \mathrm{m}^{2}\right)$.

$Q=$ Dimensionless volume flow rate $(Q=-A)$.

$q=$ Flow volume flow rate

$R=$ Bearing radius $(50 \mathrm{~mm})$.
$S=$ Speed parameter $\left(\frac{3}{40} \frac{\rho \Omega^{2} R^{2}}{p_{i}}\right)$.

$S F=$ Stiffness factor

$\mathrm{T}=$ Temperature

$u, v, w=$ Velocity components in the

$r, \theta, \varphi$ directions.

$W=$ Dimensionless load carrying capacity $\left(w / \pi R^{2} p_{i}\right)$.

$w=$ Load carrying capacity.

$z=(r-R)$

$\beta=\left(p_{i} / p_{s}\right)$.

$\boldsymbol{\theta}=$ Angle co-ordinate.

$\phi_{b}=$ Seat outer rim angle.

$\theta_{i}=$ Inlet flow angle.

$\theta_{\mathrm{e}}=$ Outlet flow angle.

$\rho=$ Lubricant density $\left(867 \mathrm{~N} . \mathrm{s}^{2} / \mathrm{m}^{4}\right)$.

$\sigma=$ Dimensionless surface roughness parameter.

$\sigma_{o}^{2}=$ Variance of the film thickness.

$\lambda=$ Bearing stiffness.

$\mu=$ Lubricant viscosity $\left(0.068 N . s / \mathrm{m}^{2}\right)$

$\Omega=$ Rotational speed.

\section{Theoretical Analysis}

The modified form of Reynolds equation derived by Dowson and Taylor [2-3] and their suggested equation for the lubricant viscosity variation applicable to the hydrosphere Figure (1) have been adopted in this study.

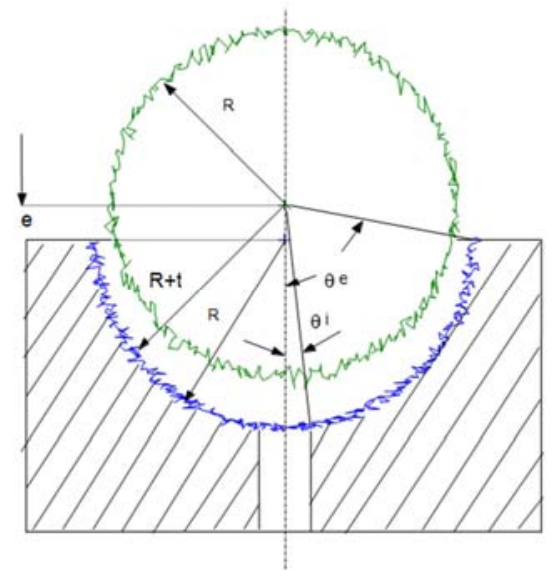

Figure 1. Bearing configuration.

The modified form of Reynolds equation derived by Dowson and Taylor [2-3] and their suggested equation for the lubricant viscosity variation applicable to the hydrosphere Figure (1) have been adopted in this study.

$$
\begin{gathered}
h^{3}\left(\frac{d P}{d \theta}-\frac{3}{20} \rho \Omega^{2} R^{2} \sin 2 \theta\right)=\frac{C}{\sin \theta} \\
\mu=\mu_{i}\left(1-K_{v} \sin \theta\right)
\end{gathered}
$$

Following Yacout and Dowson [1-3], the modified 
Reynolds equation becomes:

$$
h^{3}\left[\frac{d p}{d \theta}-\frac{3}{20} \rho \Omega^{2} R^{2} \sin 2 \theta\right]=\frac{C\left(1-K_{v} \sin \theta\right)}{\sin \theta}
$$

Taking the expectation for both sides:

$$
\begin{aligned}
& \left(h_{o}^{3}+3 \sigma_{o}^{2} h_{o}\right)\left[\frac{d p}{d \theta}-\frac{3}{20} \rho \Omega^{2} R^{2} \sin 2 \theta\right]=\frac{C\left(1-K_{v} \sin \theta\right)}{\sin \theta} \\
& \frac{d p}{d \theta}=\frac{C\left(1-k_{v} \sin \theta\right)}{\left(h_{o}^{3}+3 \sigma_{o}^{2} h_{o}\right) \sin \theta}+\frac{3}{20} \rho \Omega^{2} R^{2} \sin 2 \theta
\end{aligned}
$$

Putting the following dimensionless group and rearranging give:

$\mathrm{P}=\mathrm{p} / \mathrm{p}_{\mathrm{i}} ; \mathrm{H}=\mathrm{h}_{\mathrm{o}} / \mathrm{e}=\cos \theta ; \sigma=\sigma_{\mathrm{o}} / \mathrm{e}, \mathrm{A}=\mathrm{C} / \mathrm{e}^{3} \mathrm{P}_{\mathrm{i}} ，$ $\mathrm{S}=(3 / 40) \rho \Omega^{2} \mathrm{R}^{2}, \quad 3 \sigma^{2}=\mathrm{b}^{2}, \mathrm{~d} \theta=-(1 / \sin \theta) \mathrm{dH}$, $\mathrm{C}=-6 \mu_{\mathrm{i}} \mathrm{Q} / \pi$

$$
\begin{aligned}
\mathrm{P}= & \int \frac{-\mathrm{A}}{\left(\mathrm{H}^{3}+\mathrm{b}^{2} \mathrm{H}\right)\left(1-\mathrm{H}^{2}\right)} \mathrm{AH}-4 \mathrm{~S} \int \mathrm{HdH} \\
& +\int \frac{\mathrm{k}_{\mathrm{v}}}{\left(\mathrm{H}^{3}+\mathrm{b}^{2} \mathrm{H}\right)\left(1-\mathrm{H}^{2}\right)^{\frac{1}{2}}} \mathrm{dH}
\end{aligned}
$$

\section{Theoretical Solutions}

\subsection{Pressure Distribution}

The integration of the $1^{\text {st }}$ two parts of the pressure equation (6) could be found in Yacout [1] as:

$$
\frac{A}{b^{2}+1}\left\{\frac{1}{2 b^{2}} \ln \left(1+b^{2} \sec ^{2} \theta\right)+\ln (\tan (\theta)\}-2 S \cos ^{2} \theta+B\right.
$$

And the integration of the 3rd part of the equation could be found in the appendix (A1) as:

$$
\operatorname{Intg}=-\frac{1}{2 b^{2}}\left[\ln \frac{1+\sin \theta}{1-\sin \theta}+\frac{1}{\sqrt{1+b^{2}}} \ln \frac{\sqrt{1+b^{2}}-\sin \theta}{\sqrt{1+b^{2}}+\sin \theta}\right]
$$

Restoring the $1^{\text {st }}$ form again:

$P=\frac{A}{b^{2}+1}\left\{\frac{1}{2 b^{2}} \ln \left(1+b^{2} \sec ^{2} \theta\right)+\ln (\tan (\theta)\} \ldots .\right.$.

$-\frac{k_{v} A}{2 b^{2}}\left\{\ln \left(\frac{1+\sin \theta}{1-\sin \theta}\right)+\frac{1}{\sqrt{b^{2}+1}} \ln \left(\frac{\sqrt{b^{2}+1}-\sin \theta}{\sqrt{b^{2}+1}+\sin \theta}\right)\right\}-2 S \cos ^{2} \theta+B$

Applying the boundary conditions:

$$
\begin{aligned}
& \text { At } \theta= \theta_{i} \rightarrow P=1 \\
& \text { At } \theta= \theta_{e} \rightarrow P=0 \\
& \qquad \begin{aligned}
A= & \frac{1+2 S\left(\cos ^{2} \theta_{i}-\cos ^{2} \theta_{e}\right)}{\frac{1}{b^{2}+1}\left\{\frac{1}{2 b^{2}} \ln \left(\frac{1+b^{2} \sec ^{2} \theta_{i}}{1+b^{2} \sec ^{2} \theta_{o}}\right)+\ln \left(\frac{\tan \theta_{i}}{\tan \theta_{e}}\right\} \ldots .\right.} \\
& -\frac{k_{v}}{2 b^{2}}\left\{\ln \left(\frac{1+\sin \theta_{i}}{1-\sin \theta_{i}} \frac{1-\sin \theta_{o}}{1+\sin \theta_{o}}\right) \ldots \ldots .\right. \\
& +\frac{1}{\sqrt{b^{2}+1}} \ln \left(\frac{\sqrt{b^{2}+1}-\sin \theta_{i}}{\sqrt{b^{2}+1}+\sin \theta_{i}} * \frac{\sqrt{b^{2}+1}+\sin \theta_{e}}{\sqrt{b^{2}+1}}-\sin \theta_{e}\right.
\end{aligned}
\end{aligned}
$$

$$
\begin{aligned}
& B=2 S \cos ^{2} \theta_{e} \ldots . . \\
& -\frac{A}{b^{2}+1}\left\{\frac{1}{2 b^{2}} \ln \left(1+b^{2} \sec ^{2} \theta_{e}\right)+\ln \left(\tan \left(\theta_{e}\right)\right\} \ldots .\right. \\
& +\frac{k_{v} A}{2 b^{2}}\left\{\ln \left(\frac{1+\sin \theta_{e}}{1-\sin \theta_{e}}\right)+\frac{1}{\sqrt{b^{2}+1}} \ln \left(\frac{\sqrt{b^{2}+1}-\sin \theta_{e}}{\sqrt{b^{2}+1}+\sin \theta_{e}}\right)\right.
\end{aligned}
$$

\subsection{Load Carrying Capacity}

Following Yacout and Dowson [1-3]:

$$
\begin{aligned}
& \mathrm{W}=\pi \mathrm{R}^{2} \sin ^{2} \theta_{\mathrm{i}} \mathrm{p}_{\mathrm{i}}+2 \pi \mathrm{R}^{2} \int_{\theta_{\mathrm{i}}}^{\theta_{\mathrm{e}}} \mathrm{p} \sin \theta \cos \theta \mathrm{d} \theta \\
& \mathrm{W}=\frac{\mathrm{W}}{\pi \mathrm{R}^{2} \mathrm{p}_{\mathrm{i}}}=\sin ^{2} \theta+2 \int_{\theta_{\mathrm{i}}}^{\theta_{\mathrm{e}}} \mathrm{P} \sin \theta \cos \theta \mathrm{d} \theta \\
& \mathrm{W}=\sin ^{2} \theta+2 \int_{\theta_{\mathrm{i}}}^{\theta_{\mathrm{e}}} \mathrm{P} \sin \theta \cos \theta \mathrm{d} \theta \\
& \mathrm{W}=\sin ^{2} \theta+2 \mathrm{~F} \\
& \mathrm{~F}=\int_{\theta_{\mathrm{i}}}^{\theta_{\mathrm{e}}} \mathrm{P} \sin \theta \cos \theta \mathrm{d} \theta \\
& \int_{\theta_{\mathrm{i}}}^{\theta_{\mathrm{e}}}\left[\frac { \mathrm { A } } { \mathrm { b } ^ { 2 } + 1 } \left\{\frac{1}{2 \mathrm{~b}^{2}} \ln \left(1+\mathrm{b}^{2} \sec \mathrm{c}^{2} \theta\right)+\ln (\tan (\theta)\}\right.\right. \\
& \left.-2 \mathrm{~S} \cos ^{2} \theta+\mathrm{B}\right] \sin \theta \cos \theta \mathrm{d} \theta-\int_{\theta_{\mathrm{i}}}^{\theta_{\mathrm{e}}} \frac{\mathrm{k}_{\mathrm{v}} \mathrm{A}}{2 \mathrm{~b}^{2}}\left\{\ln \left(\frac{1+\sin \theta}{1-\sin \theta}\right)\right. \\
& \left.+\frac{1}{\sqrt{\mathrm{b}^{2}+1}} \ln \left(\frac{\sqrt{\mathrm{b}^{2}+1}-\sin \theta}{\sqrt{\mathrm{b}^{2}+1}+\sin \theta}\right)\right\} \sin \theta \cos \theta \mathrm{d} \theta \\
& =\mathrm{a}_{1}-\mathrm{a}_{2}
\end{aligned}
$$

Where:

$$
\begin{aligned}
& a_{1}=\int_{\theta_{i}}^{\theta_{e}}\left[\frac { A } { b ^ { 2 } + 1 } \left\{\frac{1}{2 b^{2}} \ln \left(1+b^{2} \sec ^{2} \theta\right)+\ln (\tan (\theta)\}\right.\right. \\
& \left.-2 S \cos ^{2} \theta+B\right] \sin \theta \cos \theta d \theta \\
& a_{2}=\int_{\theta_{i}}^{\theta_{e}} \frac{k_{v} A}{2 b^{2}}\left\{\ln \left(\frac{1+\sin \theta}{1-\sin \theta}\right)\right. \\
& \left.+\frac{1}{\sqrt{b^{2}+1}} \ln \left(\frac{\sqrt{b^{2}+1}-\sin \theta}{\sqrt{b^{2}+1}+\sin \theta}\right)\right\} \sin \theta \cos \theta d \theta
\end{aligned}
$$

The Integration of $\left(a_{1}\right)$ could be found in Yacout [1] as:

$$
\begin{aligned}
& a_{1}=A\left[\frac{b^{2}+\cos ^{2} \theta}{4 b^{2}\left(b^{2}+1\right)} \ln \left(b^{2}+\cos ^{2} \theta\right)\right. \\
& \left.-\frac{\sin ^{2} \theta}{2\left(b^{2}+1\right)} \ln (\sin \theta)-\frac{\cos ^{2} \theta}{2 b^{2}} \ln (\cos \theta)\right]_{\theta_{e}}^{\theta_{i}}+\frac{S}{2}\left[\cos ^{4} \theta\right]_{\theta_{i}}^{\theta_{e}} \\
& -B\left[\cos ^{2} \theta\right]_{\theta_{i}}^{\theta_{e}}
\end{aligned}
$$

And the integration of $\left(\mathrm{a}_{2}\right)$ in Appendix (A2) as:

$$
\mathrm{a}^{2}=\frac{\mathrm{k}_{\mathrm{v}} \mathrm{A}}{4 \mathrm{~b}^{2}}\left[\frac{\left(\cos ^{2} \theta\right)}{2} \ln \frac{(1-\sin \theta)}{(1+\sin \theta)}-\left(\frac{\mathrm{b}^{2}+\cos ^{2} \theta}{2 \sqrt{\mathrm{b}^{2}}+1}\right) \ln \frac{\left(\sqrt{\mathrm{b}^{2}+1}-\sin \theta\right)}{\left(\sqrt{\mathrm{b}^{2}+1}+\sin \theta\right)}\right]_{\theta_{\mathrm{e}}}^{\theta_{\mathrm{e}}}
$$


Then:

$$
\begin{aligned}
& \mathrm{W}=\sin ^{2} \theta+2 \mathrm{~F} \\
& \mathrm{~F}=\mathrm{a}_{1}-\mathrm{a}_{2}
\end{aligned}
$$

\subsection{Temperature Distribution}

From the appendix (A3):

$$
\begin{gathered}
\frac{\mathrm{dT}}{\mathrm{d} \theta}=\left(\frac{\mathrm{p}_{\mathrm{i}}}{\rho \mathrm{c}_{\mathrm{v}}}\right) \frac{\left(\frac{\mathrm{dP}}{\mathrm{d} \theta}\right)^{2}-4 \mathrm{~S}\left(\frac{\mathrm{dP}}{\mathrm{d} \theta}\right) \sin (2 \theta)+\frac{(\mathrm{S} \sin 2 \theta)^{2}}{0.21}}{\left(2 \sin 2 \theta-\frac{\mathrm{dP}}{\mathrm{d} \theta}\right)} \\
+\frac{(\text { Const }) \sin ^{2} \theta \sec ^{4} \theta\left(1-\mathrm{k}_{\mathrm{v}} \sin \theta\right)^{2}}{\left(2 \sin 2 \theta-\frac{\mathrm{dP}}{\mathrm{d} \theta}\right)}=\mathrm{X} \\
\frac{\Delta \mathrm{T}}{\Delta \theta}=\mathrm{X} \\
\mathrm{T}_{\mathrm{n}}=\mathrm{T}_{\mathrm{n}-1}+\mathrm{X} \Delta \theta \\
\text { Const }=\left(\frac{160 \mathrm{~S} \mu_{\mathrm{i}}^{2}}{\rho \mathrm{p}_{\mathrm{i}} \mathrm{R}^{2} \mathrm{~K}_{\mathrm{e}}^{4}}\right) \\
\mu=\mu_{\mathrm{i}}(1-\mathrm{K} \sin \theta)
\end{gathered}
$$

\subsection{Frictional Torque}

Following Yacout and Dowson [1-3]:

$$
\begin{gathered}
m=\int_{\theta_{i}}^{\theta_{e}} d m=\frac{2 \pi \Omega R^{4}}{e} \int_{\theta_{i}}^{\theta_{e}} \frac{\mu \sin ^{3} \theta}{h} d \theta \\
\mu=\mu_{i}\left(1-k_{v} \sin \theta\right) \\
\frac{m e}{2 \pi \mu_{i} \Omega R^{4}}=\int_{\theta_{i}}^{\theta_{e}} \frac{\left(1-k_{v} \sin \theta\right) \sin ^{3} \theta}{h} d \theta \\
M=\int_{\theta_{i}}^{\theta_{e}} \frac{\left(1-k_{v} \sin \theta\right) \sin ^{3} \theta}{h} d \theta \\
M=\int_{\theta_{i}}^{\theta_{e}} \frac{\left(1-k_{v} \sin \theta\right) \sin ^{3} \theta}{h} d \theta \\
E\left(\frac{1}{h}\right)=\frac{h^{2}+\sigma^{2}}{h^{3}}=\frac{\cos ^{2} \theta+\sigma^{2}}{\cos ^{3} \theta}
\end{gathered}
$$

Taking the expectation of both sides:

$$
\begin{gathered}
M=\int_{\theta_{i}}^{\theta_{e}} \frac{\left(\cos ^{2} \theta+\sigma^{2}\right)\left(1-k_{v} \sin \theta\right) \sin ^{3} \theta}{\cos ^{3} \theta} d \theta \\
M=\int_{\theta_{i}}^{\theta_{e}}-\frac{\left(\cos ^{2} \theta+\sigma^{2}\right)\left(1-k_{v} \sin \theta\right) \sin ^{2} \theta}{\cos ^{3} \theta} d(\cos \theta) \\
M=\int_{\theta_{i}}^{\theta_{e}}-\frac{\left(\cos ^{2} \theta+\sigma^{2}\right)\left(1-k_{v} \sin \theta\right)\left(1-\cos ^{2} \theta\right)}{\cos ^{3} \theta} d(\cos \theta)
\end{gathered}
$$

$$
M=\int_{\theta_{i}}^{\theta_{e}} \frac{\left(\cos ^{2} \theta+\sigma^{2}\right)\left(1-k_{v} \sin \theta\right)\left(\cos ^{2} \theta-1\right)}{\cos ^{3} \theta} d(\cos \theta)
$$

The Integration could be found in the Appendix (A4) as:

$$
\begin{aligned}
& M=\left[\frac{\cos ^{2} \theta}{2}+\left(\sigma^{2}-1\right) \ln (\cos \theta)+-\frac{\sigma^{2}}{2 \cos ^{2} \theta}\right]_{\theta_{i}}^{\theta_{e}}- \\
& k_{v}\left[\left(\sigma^{2}-1\right)\{\sin \theta-\ln (\tan \theta+\sec \theta)\}-\right. \\
& \left.\frac{\sigma^{2}}{2}\{\ln (\sec \theta+\tan \theta)-\sec \theta \tan \theta\}-\frac{\sin ^{3} \theta}{3}\right]_{\theta_{i}}^{\theta_{e}}
\end{aligned}
$$

\subsection{Volume Flow Rate}

From Yacout [1]:

$$
Q=-A
$$

\subsection{Friction Factor}

From Yacout [1]:

$$
F=M / W
$$

\subsection{Power Factor}

From Yacout [1]:

$$
h_{f}=\frac{\pi Q}{W^{2} \cos ^{3} \theta_{e}}
$$

\subsection{Stiffness Factor}

From Yacout [1]:

$$
S F=-(\bar{\beta} W+\beta \bar{W})
$$

\section{Results}

Where the main objective of this study is to find out the bearing thermal behavior under the lubricant viscosity variation in the presence of the centripetal inertia and the surface roughness, and because of the complexity of the theoretical solution it was necessary to compare between different forms of viscosity equations to adopt the one which can help in facilitating the theoretical derivation of some equations that represent the bearing characteristics. Deriving such equations it was preferably applied to the un-recessed fitted type of bearings to predict its behavior. The bearing characteristics such as pressure distribution, temperature distribution, load carrying capacity, flow rate, frictional torque, friction factor and stiffness factor have been calculated for the bearing with hemispherical and partially hemispherical seats. Figures (2-13) represent the bearing with hemispherical and partially hemispherical seats respectively.

\section{Discussion}

It is found to be necessary to study the bearing thermal behavior since it hasn't been accomplished in Yacout [1]. The visions of Dowson [2,3] and Essam and Farid [4, 5] of the 
lubricant viscosity and temperature gradient for the hydrostatic spherical bearing respectively have been adopted. The example of the designed bearing offered in Yacout [1] has been used as a guide in the research.

\subsection{The Pressure Distribution}

Figures $(2,3)$ represent the effects of the different parameters on the pressure distribution for a bearing with hemispherical and partial hemispherical seats.

\subsubsection{The Effect of the Viscosity}

Tthe efect of the viscosity, represented by the viscosity variation constant, on thepressure could be easly observed where it could be practically considered insignificant and can be ignored in the case of the hemispherical seat due the high effect of the inertia whereas in the partial case it is clearly appreciable because of the inertialesser effect, Subfigures (2a and $3 a)$.

\subsubsection{The Effect of the Inertia}

The inertia represented by the speed parameter Yacout [1] and Dowson [2, 3] shows a dominant role where it highly increases the pressure specially with the hemispherical seat despite its lesser effect with the partial hemispherical one subfigures $(2 \mathrm{~b}, 3 \mathrm{~b})$.

\subsubsection{The Effect of the Eccentricity}

Subfigures (2c, 3c) show the eccenrticity effect on the pressure where it is clear that the pressure decreases with the increase in the eccentricity. This insignificant decrease inthepressure despite the presence of the vicosity variation gives an indication of a highly stiffened bearing configuration, the bearing design example Yacout [1].

\subsubsection{The Effect of the Surface Roughness}

It is obviously clear from the subfigures $(2 \mathrm{~d}, 3 \mathrm{~d})$ that the two bearing configurations haven't been significantly affected by the surface roughness. Comparing these results with those in Yacout [1] no remarkable difference could be observed despite the viscosity variability which leads to the prediction that the bearing stiffness will not be significantly affected by the viscosity variation.
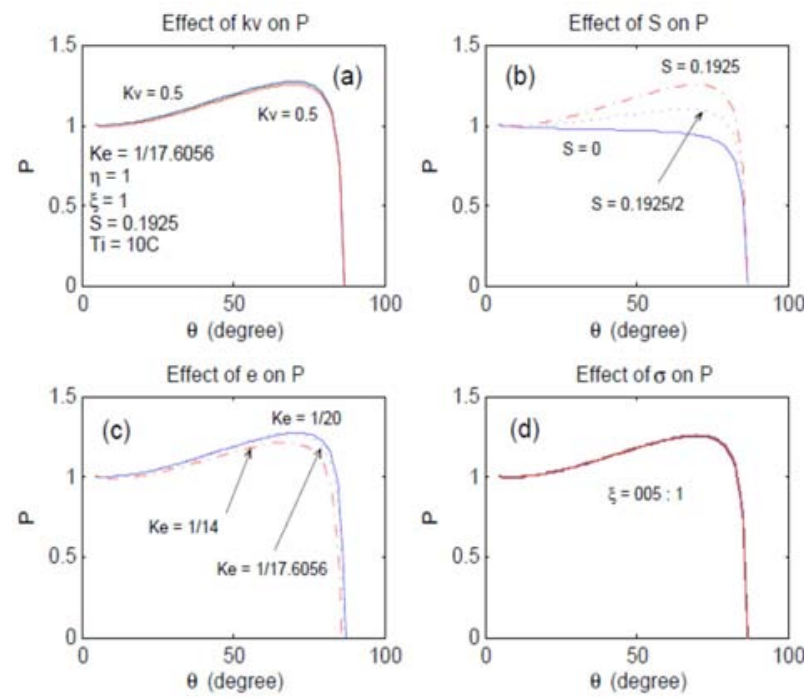
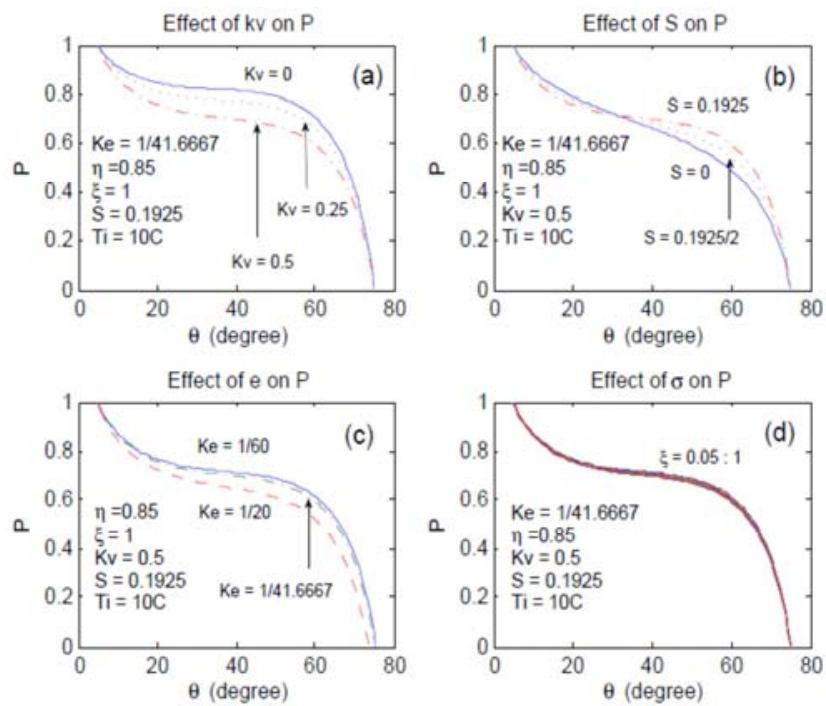

Figure 3. Partial hemispherical seat.

\subsection{The Load Carrying Capacity}

Figures $(4,5)$ represent the load carrying capacity for a bearing with hemispherical and partial hemispherical seats.
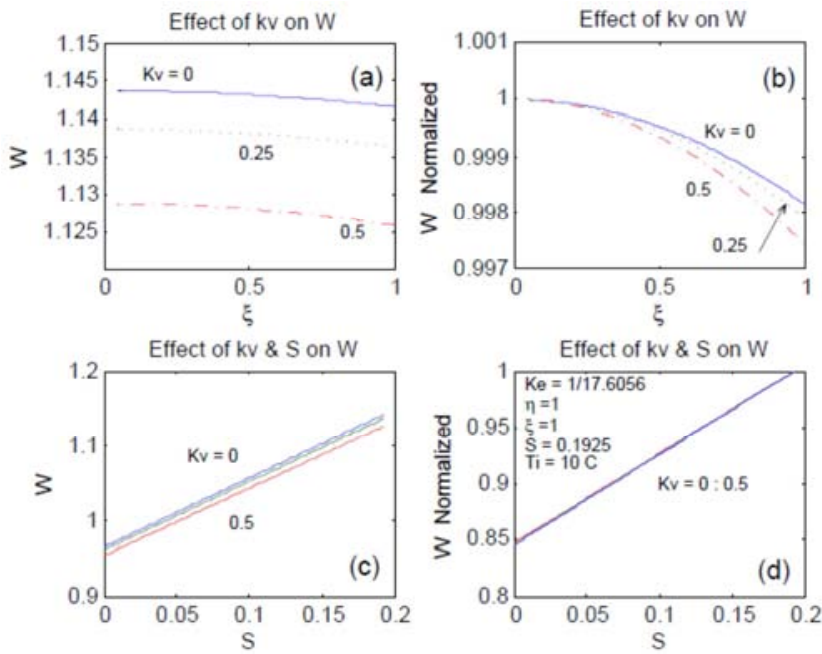

Figure 4. Hemispherical seat.
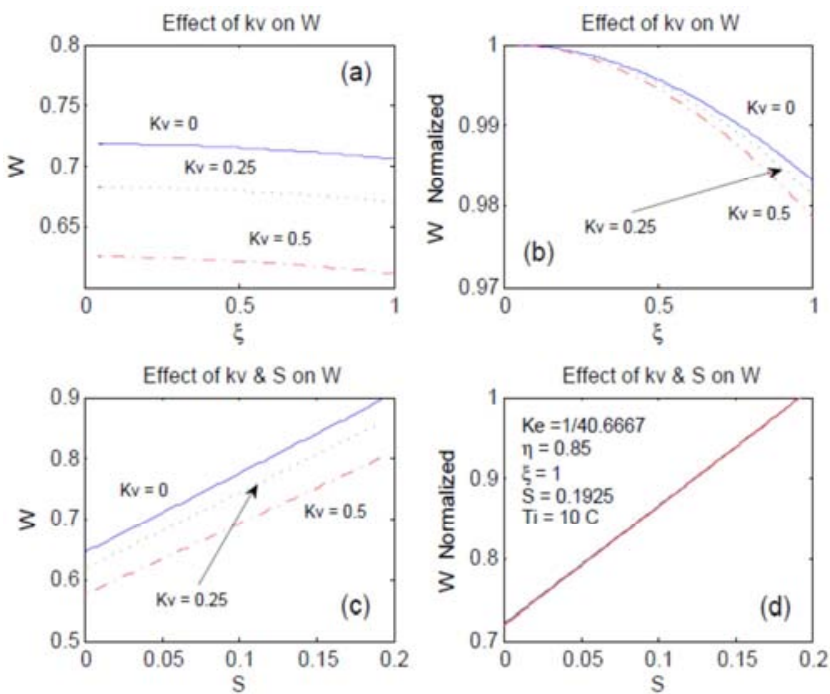

Figure 5. Partial hemispherical seat.

Figure 2. Hemispherical seat 


\subsubsection{The Effect of the Viscosity}

Subfigures $(4 a, 5 a)$ show the load decrease with the increase in both of the viscosity variation costant and the surface roughness. Normalizing the load, Subfigures $(4 b, 5 b)$ show that the decrease in the load- due to the viscosity variation constant increase- is increasing as the surface roughness increases, i.e, at a point with certain value of the surface roughness parameter the decrease in the load due to the viscosity variation will increase at another point with higher value. And the relatively whole loss in the load along the surface parameter scale will increase as the vicosity variation constant increases.

\subsubsection{The Effect of the Inertia}

As seen from subfigures $(4 \mathrm{c}, 5 \mathrm{c})$, the load is positively affected by the inertia and negatively by the viscosity variation. It is also clear that the load decrease due to the viscosity variation in the case of hemispherical seat is less than that of the partial hemisperical one because of the more effective role of the inertia as said before in the pressure. Normalizing the load subfigures $(4 \mathrm{~d}, 5 \mathrm{~d})$, show that the load decrease due to the viscosity variation is not affected by the increase in the inertia (speed parameter) and the relatively net gain in the load due to the inertia will not be affected by the viscosity variation.

\subsection{The Volume Flow Rate, the Frictional Factor, the Friction Factor and the Power Factor}

Figures $(6,7)$ represent the volume flow rate, the frictional torque, the friction factor and the power factor for the same bearing with the hemispherical and the partial hemispherical seats.

It could be seen from the two figures that the volume flow rate and the power factor increase with the increase in the viscosity variation constant, subfigures $(6 a, d)$ and subfigures $(7 \mathrm{a}, \mathrm{d})$ while the frictional torque and the friction factor decrease subfigures $(6 \mathrm{~b}, \mathrm{c})$ and subfigures

$(7 \mathrm{~b}, \mathrm{c})$. It looks reasonable and logical because of the viscosity decrease.
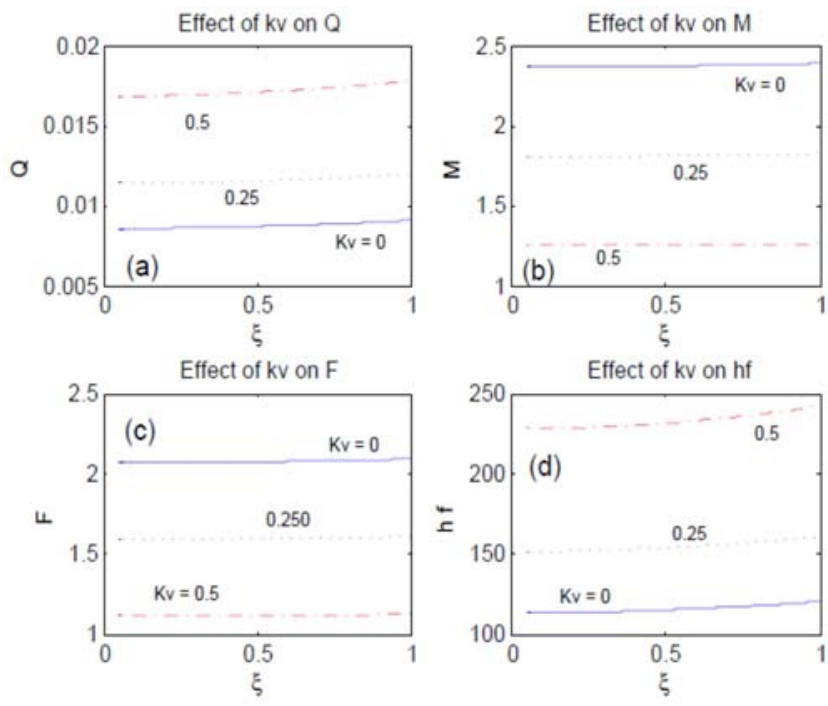

Figure 6. Hemispherical seat.
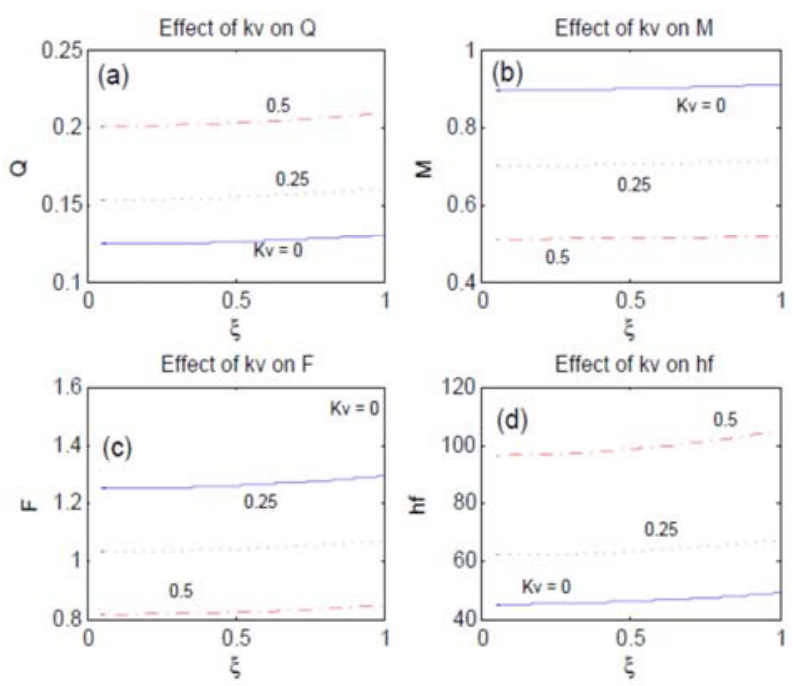

Figure 7. Partial hemispherical seat.

\subsection{The Temperature Distribution and Rise}

Figures $(8,9)$ represent the effects of the viscosity variation, the inertia, the eccentricity and surface roughness on the temperature distribution.
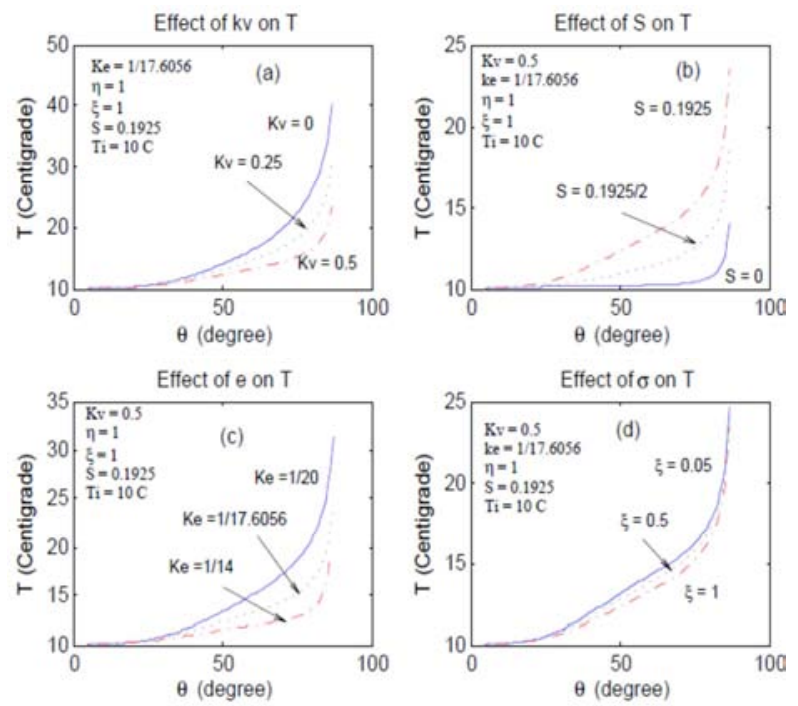

Figure 8. Hemispherical seat.
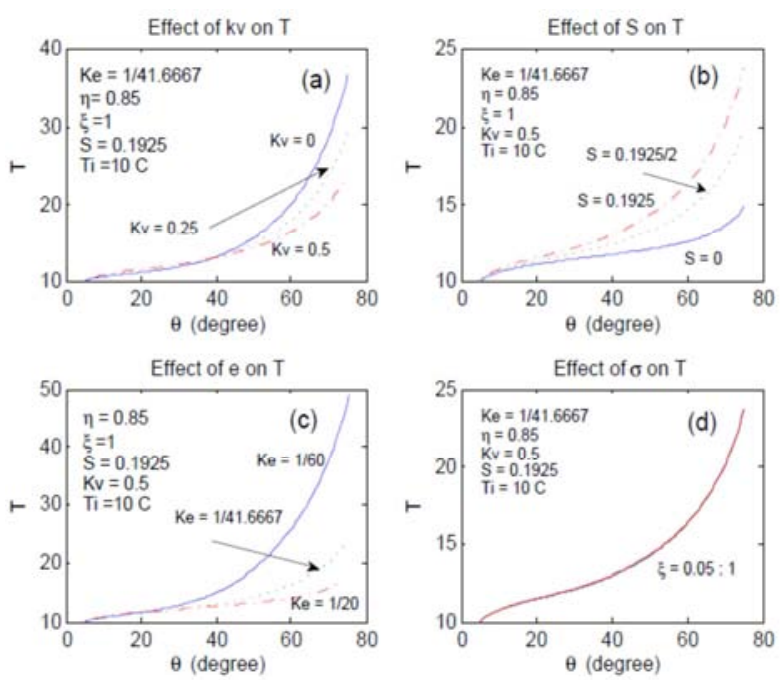

Figure 9. Partial hemispherical seat. 
It is clear that the temperature decreases with the viscosity variation constant increase, subfigures $(8 a, 9 a)$.

\subsubsection{The Effect of the Viscosity Variation Constant}

It is clear that the temperature decreases with the viscosity variation constant increase, subfigures $(8 \mathrm{a}, 9 \mathrm{a})$.

\subsubsection{The Effect of the Inertia}

Subfigures $(8 \mathrm{~b}, 9 \mathrm{~b})$ shows that the inertia plays an important role in raising the temperature.

\subsubsection{The Effect of the Eccentricity}

Subfigures (8c, 9c) shows that the temperature is positively affected with decrease in the eccentricity.

\subsubsection{The effect Of the Surface Roughness}

Subfigures $(8 \mathrm{~d}, 9 \mathrm{~d})$ shows that the surface roughness has the least effect on the temperature where it could be practiclly ignored.

Generally, it could be said that Just a look at the pressure equation shows its complicated relation with the inertia, the eccentricity, the surface roughness and the viscosity; and another look at the equation of the temperature gradient shows its complicated relation with the pressure gradient, the inertia and viscosity. The study of these complicated relations controlling the temperature rise could facilitate the designer job.

\subsection{The Stiffness Factor and the Central Pressure Ratio}

Figures $(10,11)$ represent the effects of the viscosity variation constant on the stiffness factor and the central pressure ratio.

\subsubsection{The Stiffness Factor}

The bearing with the hemispherical seat shows no remarkable effect on the stiffness factor due to the vicosity variation whereas the bearing with the partial hemispherical seat shows decrease with the viscosity variation constant, subfigures $(10 \mathrm{a}, 11 \mathrm{a})$. The normalization of the stiffness factor shows that the bearing behavior hasn't been affected regardless the seat type i.e, the stiffness factor versus the surface roughness has a fixed shape, subfigures $(10 \mathrm{~b}, 11 \mathrm{~b})$.
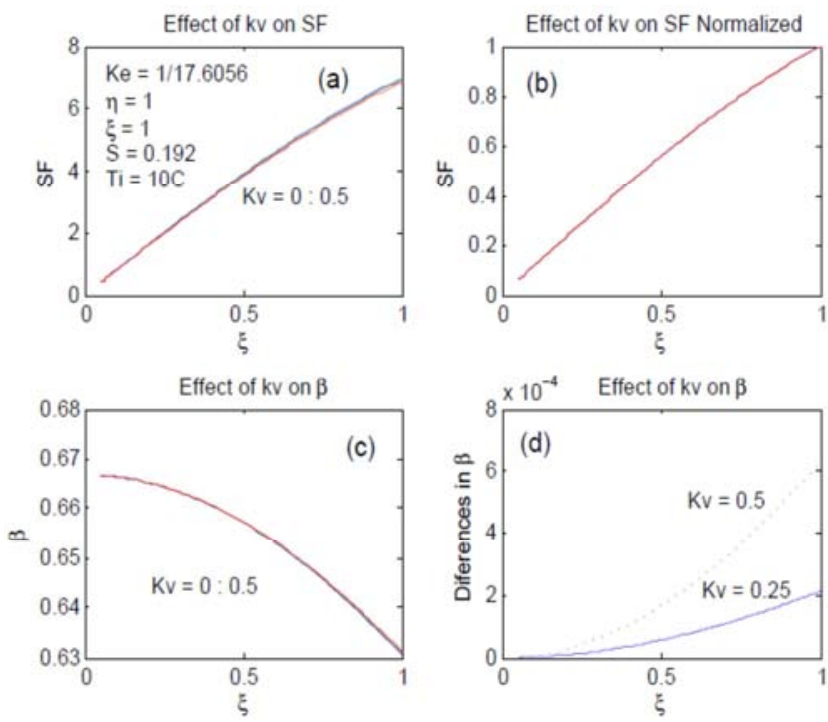

\subsubsection{The Central Pressure Ratio}

Subfigures (10c, 11c) show the effect of the central pressure ratio with the viscosity variation. Despite the unsean effect in the case of the hemispherical seat Subfigures (10d, 11d) reveal the the central pressure ratio increase with the viscosity variation constant.
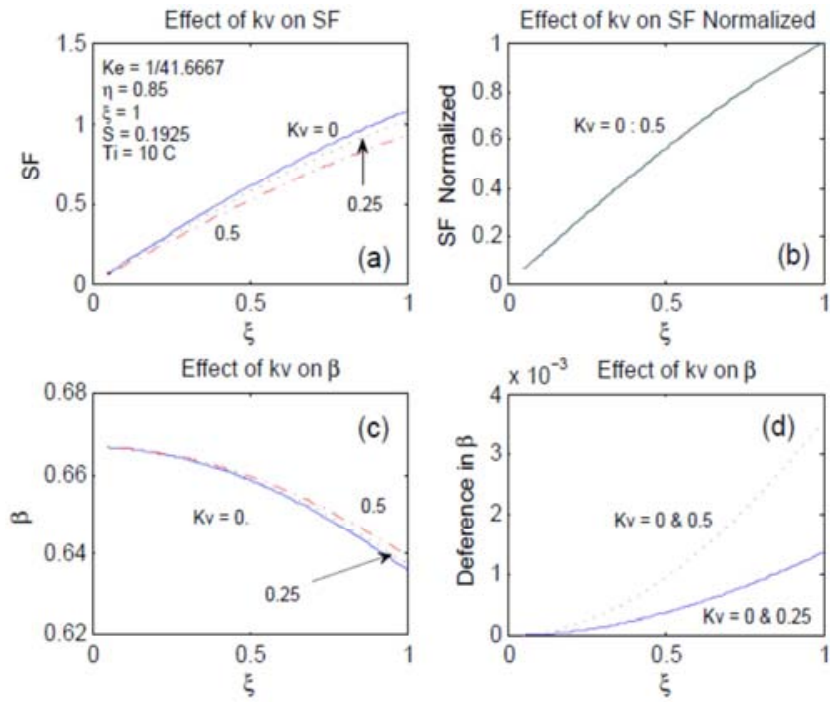

Figure 11. Partial hemispherical seat.

\section{Testing the Designed Bearing}

One of the objectives of this study is testing the bearing designed by Yacout [1] showing the performance deviation when considering the variable viscosity. The bearing has:

$$
\begin{aligned}
& \mathrm{R}=50 \mathrm{~mm}, \phi_{\mathrm{i}}=5, \quad \eta=1.0, \xi=0.05, \mathrm{~N}=100 \mathrm{rps}, \\
& \mathrm{N}=100 \mathrm{rps}, \rho=867 \mathrm{~N} . \mathrm{s}^{2} / \mathrm{m}^{4}, \beta=2 / 3, \mu=0.068 \mathrm{~N} . \mathrm{s} / \mathrm{m}^{2}, \\
& \mathrm{~K}_{\mathrm{e}}=1 / 17.6056, \mathrm{~K}_{\mathrm{v}}=0, \mathrm{~K}_{\mathrm{v}}=0.5
\end{aligned}
$$
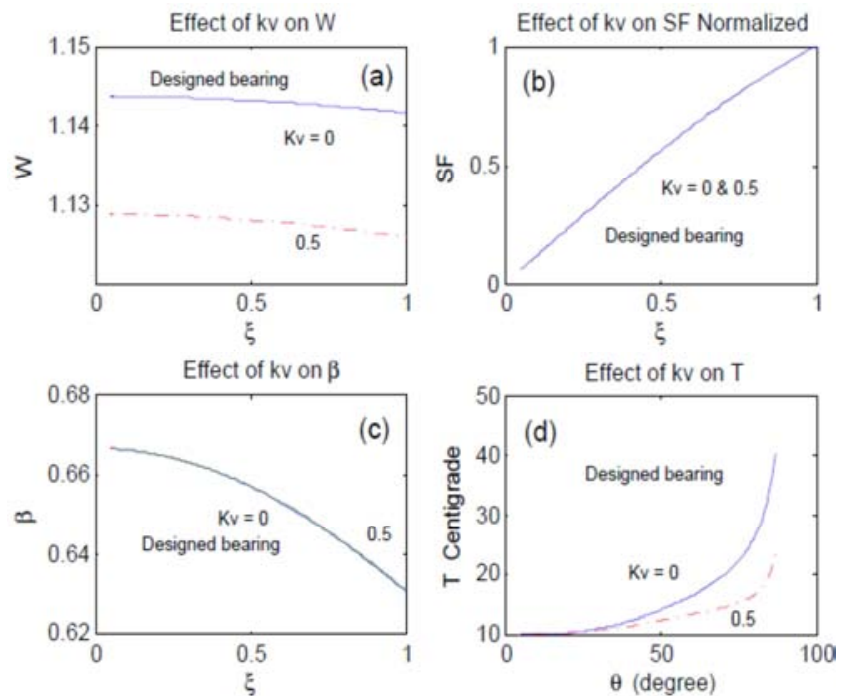

Figure 12 designed bearing

Figure 10. Hemispherical seat. 

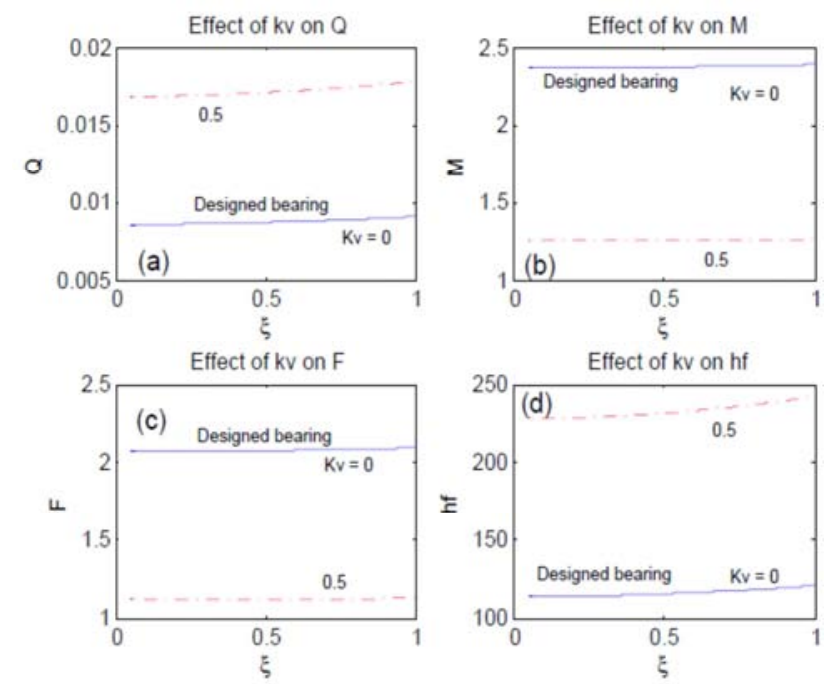

Figure 13. Designed bearing.

Table 1. Comparison between the two cases.

\begin{tabular}{lllll}
\hline & \multicolumn{2}{l}{ Hemi. seat } & & \\
& \multicolumn{1}{c}{$K_{v}=\mathbf{0}$} & $K_{v}=\mathbf{0 . 5}$ & Deviation \% & Observation \\
\hline W & 1.144 & 1.129 & -1.3 & Decrease Fair \\
SF & & & Unremarkable & Insignificant Excellent \\
B & & & Unremarkable & Insignificant Excellent \\
T & 40.18 & 32.52 & -41 & Decrease Excellent \\
Q & 0.0091 & 0.0178 & +96 & Increase, Fair \\
M & 2.391 & 1.265 & -47 & Decrease excellent \\
F & 2.094 & 1.124 & -46 & Decrease excellent \\
$h_{f}$ & 120.3 & 242.2 & +101 & Increase, fair \\
\hline
\end{tabular}

Using the constant of the variable viscosity as zero in the calculations gives the same results as in Yacout [1] where the viscosity is constant. When using this constant (variable viscosity constant) of 0.5 as adopted in this research and in Dowson [3] it gives the bearing performance under the variable viscosity.

The test results are represented by figures $(12-13)$ in addition to table 1 .

As seen from figures $(12,13)$ and table 1 , the increase in the volume flow rate, in turn the increase in the power factor, is approximately doubled. The load shows $1.3 \% \max$ difference (could be excellent). The temperature, the frictional torque and the friction factor show more than $40 \%$ decrease while the stiffness factor and the central pressure ratio show unremarkable differences. Finally it could be said that the lonely drawback of this designed bearing is the power factor which can't be avoided because of the increase in the volume flow rate.

It is worthy to say that the bearing in the experimental study of Dowson [3] was running at half of the speed of this bearing and the temperature rise was 40 degrees centigrade while temperature rise in this design is 30 and 14 degrees centigrade in the cases of constant and variable viscosity respectively.

Hence, the bearing designed in Yacout [1] could be considered practically excellent.

\section{Conclusion}

Based on the conception of the stochastic Reynolds equation (by the author), adopting the viscosity variation form suggested by Dowson and the temperature gradient equation derived by Essam and Farid (checked by the author because of its wrong form in the reference), the isothermal stochastic Reynolds equation has been derived and applied to the un-recessed hydrostatic thrust spherical fitted type of bearings to study its performance. The study shows that:

1. The load, the frictional torque, the friction factor, the stiffness and the temperature rise are less in the case of the isothermal solution.

2. The volume flow rate and the power factor have approximately doubled. The central pressure ratio shows little increase at high surface roughness..

3 . The temperature decreases with the increase of variation viscosity constant and the eccentricity.

4. The design technique of this type of bearings in the previous study by the author could be considered highly trusted.

\section{Future Work}

The $2^{\text {nd }}$ part of the research handles the recessed fitted type re- designing the bearing based on the same conditions in addition to the mean effective viscosity.

\section{Appendix}

\section{A1- Integration of the 3rd Part of the Pressure Equation}

$$
\int \frac{A K_{v}}{\left(H^{3}+b^{2} H\right)\left(1-H^{2}\right)^{\frac{1}{2}}} d H
$$

Put:

$$
\begin{gathered}
X=(\sin \theta) \\
X^{2}=\left(1-H^{2}\right) \\
H=\left(1-X^{2}\right)^{\frac{1}{2}} \\
H=\left(1-X^{2}\right)^{\frac{1}{2}} \\
d H=-\frac{X d X}{\left(1-X^{2}\right)^{\frac{1}{2}}}
\end{gathered}
$$

Eq. (18) becomes:

$$
\begin{gathered}
\frac{1}{\left\{\left(1-X^{2}\right)^{\frac{3}{2}}+b^{2}\left(1-X^{2}\right)^{\frac{1}{2}}\right\} X} * \frac{-X}{\left(1-X^{2}\right)^{\frac{1}{2}}} d X \\
\frac{-d X}{\left(1-X^{2}\right)\left[\left(b^{2}+1\right)-X^{2}\right)}
\end{gathered}
$$

Put:

$$
\begin{aligned}
& \left(b^{2}+1\right)=m^{2} \\
& \frac{-d X}{\left(1-X^{2}\right)\left(m^{2}-X^{2}\right)}
\end{aligned}
$$

Finding the partial fraction of Eq. (19): 


$$
\frac{1}{\left(1-X^{2}\right)\left(m^{2}-X^{2}\right)}=\frac{a m}{1-X}+\frac{a m}{1+X}-\frac{a}{m-X}-\frac{a}{m+X}
$$

$\frac{a m(1+X)\left(m^{2}-X^{2}\right)+a m(1-X)\left(m^{2}-X^{2}\right)-a\left(1-X^{2}\right)(m+X)-a\left(1-X^{2}\right)(m+X)}{\left(1-X^{2}\right)\left(m^{2}-X^{2}\right)}$

$$
\begin{gathered}
\frac{2 a m\left[m^{2}-X^{2}-1+X^{2}\right]}{\left(1-X^{2}\right)\left(m^{2}-X^{2}\right)} \\
\frac{2 a m\left(m^{2}-1\right)}{\left(1-X^{2}\right)\left(m^{2}-X^{2}\right)} \\
2 a m\left(m^{2}-1\right)=1 \\
a=\frac{1}{2 m\left(m^{2}-1\right)} \\
\frac{1}{\left(1-X^{2}\right)\left(m^{2}-X^{2}\right)}=\frac{1}{\frac{1}{2\left(m^{2}-1\right)}\left[\frac{1}{(1-X)}+\frac{1}{1+X}-\frac{1}{m(m-X)}-\frac{1}{m(m+X)}\right]}
\end{gathered}
$$

Substituting from (21) into (21), eq. (19) becomes:

$$
-\frac{1}{2\left(m^{2}-1\right)}\left[\frac{1}{(1-X)}+\frac{1}{1+X}-\frac{1}{m(m-X)}-\frac{1}{m(m+X)}\right] d X
$$

The integration of Eq. (22) gives:

$$
\operatorname{In} \operatorname{tg}=\frac{1}{2\left(1-\mathrm{m}^{2}\right)}\left[\ln \frac{(1+X)}{(1-X)}+\frac{1}{m} \ln \frac{(m-X)}{(m+X)}\right]
$$

Replacing $\mathrm{m}$ and $\mathrm{X}$ :

$$
\operatorname{Intg}=-\frac{1}{b^{2}}\left[\ln \frac{1+\sin \theta}{1-\sin \theta}+\frac{1}{\sqrt{1+b^{2}}} \ln \frac{\sqrt{1+b^{2}}-\sin \theta}{\sqrt{1+b^{2}}+\sin \theta}\right]
$$

Then integration of equation (18) becomes:

$$
-\frac{\mathrm{AK}_{\mathrm{v}}}{\mathrm{b}^{2}}\left[\ln \frac{1+\sin \theta}{1-\sin \theta}+\frac{1}{\sqrt{1+\mathrm{b}^{2}}} \ln \frac{\sqrt{1+\mathrm{b}^{2}}-\sin \theta}{\sqrt{1+\mathrm{b}^{2}}+\sin \theta}\right]
$$

\section{A2- The Load Carrying Capacity Derivation}

Following Yacout and Dowson [1- 3], the modified Reynolds equation:

$$
\begin{aligned}
& \mathrm{W}=\pi \mathrm{R}^{2} \sin ^{2} \theta_{\mathrm{i}} \mathrm{p}_{\mathrm{i}}+2 \pi \mathrm{R}^{2} \int_{\theta_{\mathrm{i}}}^{\theta_{\mathrm{e}}} \mathrm{p} \sin \theta \cos \theta d \theta \\
& \mathrm{W}=\frac{\mathrm{W}}{\pi \mathrm{R}^{2} \mathrm{p}_{\mathrm{i}}}=\sin ^{2} \theta+2 \int_{\theta_{\mathrm{i}}}^{\theta_{\mathrm{e}}} \mathrm{P} \sin \theta \cos \theta d \theta \\
& \mathrm{W}=\sin ^{2} \theta+2 \int_{\theta_{\mathrm{i}}}^{\theta_{\mathrm{e}}} \mathrm{P} \sin \theta \cos \theta \mathrm{d} \theta \\
& \mathrm{W}=\sin ^{2} \theta+2 \mathrm{~F}
\end{aligned}
$$

$$
\begin{aligned}
& \mathrm{F}=\int_{\theta_{\mathrm{i}}}^{\theta_{\mathrm{e}}} \mathrm{P} \sin \theta \cos \theta \mathrm{d} \theta \\
& =\int_{\theta_{\mathrm{i}}}^{\theta_{\mathrm{e}}}\left[\frac { \mathrm { A } } { \mathrm { b } ^ { 2 } + 1 } \left\{\frac{1}{2 \mathrm{~b}^{2}} \ln \left(1+\mathrm{b}^{2} \sec ^{2} \theta\right)+\ln (\tan (\theta)\}\right.\right. \\
& \left.-2 \mathrm{Cos}^{2} \theta+\mathrm{B}\right] \sin \theta \cos \theta \mathrm{d} \theta \\
& -\int_{\theta_{\mathrm{i}}}^{\theta_{\mathrm{e}}} \frac{\mathrm{K}_{\mathrm{v}} \mathrm{A}}{2 \mathrm{~b}^{2}}\left\{\ln \left(\frac{1+\sin \theta}{1-\sin \theta}\right)\right. \\
& \left.+\frac{1}{\sqrt{\mathrm{b}^{2}+1}} \ln \left(\frac{\sqrt{\mathrm{b}^{2}+1}-\sin \theta}{\sqrt{\mathrm{b}^{2}+1}+\sin \theta}\right)\right\} \sin \theta \cos \theta \mathrm{d} \theta \\
& =\mathrm{a}_{1}-\mathrm{a}_{2} \\
& \mathrm{a}_{1}=\int_{\theta_{\mathrm{i}}}^{\theta_{\mathrm{e}}}\left[\frac { \mathrm { A } } { \mathrm { b } ^ { 2 } + 1 } \left\{\frac{1}{2 \mathrm{~b}^{2}} \ln \left(1+\mathrm{b}^{2} \sec { }^{2} \theta\right)+\ln (\tan (\theta)\}\right.\right. \\
& \left.-2 \mathrm{~S} \cos ^{2} \theta+\mathrm{B}\right] \sin \theta \cos \theta \mathrm{d} \theta \\
& +\frac{\mathrm{a}_{2}}{=} \int_{\theta_{\mathrm{i}}}^{\theta_{\mathrm{e}}} \frac{\mathrm{K} \mathrm{v}}{2 \mathrm{~b}^{2}}\left\{\ln \left(\frac{1+\sin \theta}{1-\sin \theta}\right)\right. \\
& \left.\sqrt{\mathrm{b}^{2}+1} \ln \left(\frac{\sqrt{\mathrm{b}^{2}+1}-\sin \theta}{\sqrt{\mathrm{b}^{2}+1}+\sin \theta}\right)\right\} \sin \theta \cos \theta \mathrm{d} \theta
\end{aligned}
$$

The Integration of $\left(a_{1}\right)$ could be found in Yacout [1] as:

$$
\begin{aligned}
& a_{1}=A\left[\frac{b^{2}+\cos ^{2} \theta}{4 b^{2}\left(b^{2}+1\right)} \ln \left(b^{2}+\cos ^{2} \theta\right)-\frac{\sin ^{2} \theta}{2\left(b^{2}+1\right)} \ln (\sin \theta)\right. \\
& \left.-\frac{\cos ^{2} \theta}{2 b^{2}} \ln (\cos \theta)\right]_{\theta_{e}}^{\theta_{i}}+\frac{S}{2}\left[\cos ^{4} \theta\right]_{\theta_{i}}^{\theta_{e}}-B\left[\cos ^{2} \theta\right]_{\theta_{i}}^{\theta_{e}}
\end{aligned}
$$

Put:

$$
\mathrm{m}^{2}=\left(\mathrm{b}^{2}+1\right) \quad \& \quad \sin \theta=\mathrm{X}
$$

Then:

$$
\cos \theta=\left(1-X^{2}\right)^{1 / 2}, \frac{d X}{d \theta}=\cos \theta, d \theta=\frac{d X}{\left(1-X^{2}\right)^{1 / 2}}
$$

Then:

$$
\begin{aligned}
& a_{2}=\frac{K_{v} A}{2 b^{2}} \int_{\theta_{i}}^{\theta_{e}}\left[\ln \left(\frac{1+X}{1-X}\right)+\frac{1}{m} \ln \left(\frac{m-X}{m+X}\right)\right] X\left(\frac{d X}{d \theta}\right)(d \theta) \\
& =\frac{K_{v} A}{2 b^{2}} \int_{\theta_{i}}^{\theta_{e}}\left[\ln \left(\frac{1+X}{1-X}\right)+\frac{1}{m} \ln \left(\frac{m-X}{m+X}\right)\right] X d X \\
& =\frac{K_{v} A}{2 b^{2}} \int_{\theta_{i}}^{\theta_{i}}\left[X \ln \left(\frac{1+X}{1-X}\right)+\frac{X}{m} \ln \left(\frac{m-X}{m+X}\right)\right] d X \\
& =\frac{K_{v} A}{2 b^{2}} \int_{\theta_{i}}^{\theta_{e}}[X \ln (1+X)-X \ln (1-X) \\
& \left.+\frac{X}{m} \ln (m-X)-\frac{X}{m} \ln (m+X)\right] d X \\
& =\frac{K_{v} A}{2 b^{2}} \int_{\theta_{i}}^{\theta_{e}}\left[t_{1}-t_{2}+t_{3}-t_{4}\right] d X
\end{aligned}
$$




$$
\begin{aligned}
& \mathrm{t}_{1}=X \ln (1+X) \\
& \mathrm{t}_{2}=X \ln (1-X) \\
& \mathrm{t}_{3}=\frac{X}{m} \ln (\mathrm{m}-\mathrm{X}) \\
& \mathrm{t}_{4}=\frac{X}{\mathrm{~m}} \ln (\mathrm{m}+\mathrm{X})
\end{aligned}
$$

Integration of each term:

$$
\begin{aligned}
& \int_{\theta_{i}}^{\theta_{c}} t_{1} d X=\int_{\theta_{i}}^{\theta_{c}} X \ln (1+X) d X=\int_{\theta_{i}}^{\theta_{e}} X \ln (1+X) d X \\
& =\int_{\theta_{i}}^{\theta_{e}}[(1+X) \ln (1+X)-\ln (1+X)] d(1+X) \\
& \left.=\int_{\theta_{\mathrm{i}}}^{\theta_{e}}(1+\mathrm{X}) \ln (1+\mathrm{X}) \mathrm{d}(1+\mathrm{X})-\int_{\theta_{\mathrm{i}}}^{\theta_{e}} \ln (1+\mathrm{X})\right] \mathrm{d}(1+\mathrm{X}) \\
& =\left[\frac{(1+X)^{2}}{2}\left\{\ln (1+X)-\frac{1}{2}\right\}\right]_{\theta_{\mathrm{i}}}^{\theta_{\mathrm{e}}}-[(1+\mathrm{X})\{\ln (1+\mathrm{X})-1\}]_{\theta_{\mathrm{i}}}^{\theta_{\mathrm{e}}} \\
& =\left[\frac{\left(X^{2}-1\right)}{2} \ln (1+X)-(1+X)\left\{\frac{(X-3)}{4}\right\}\right]_{\theta_{i}}^{\theta_{e}} \\
& =\frac{\left(X^{2}-1\right)}{2}\left[\ln (1+X)-\frac{3-X}{2(1-X)}\right]_{\theta_{i}}^{\theta_{e}} \\
& =\frac{\left(1-X^{2}\right)}{2}\left[\frac{3-X}{2(1-X)}-\ln (1+X)\right]_{\theta_{i}}^{\theta_{e}} \\
& \text { Then: } \\
& \int_{\theta_{i}}^{\theta_{e}} t_{1} d X=\frac{\left(1-X^{2}\right)}{2}\left[\frac{3-X}{2(1-X)}-\ln (1+X)\right]_{\theta_{i}}^{\theta_{e}}
\end{aligned}
$$

Integration of $\left(t_{2}\right)$ could be done as $\left(t_{1}\right)$ with changing the sign of $(\mathrm{X})$ to be:

$$
\begin{aligned}
\int_{\theta_{i}}^{\theta_{e}} t_{2} d X & =X \ln (1-X) d X \\
& =\frac{\left(1-X^{2}\right)}{2}\left[\frac{3+X}{2(1+X)}-\ln (1-X)\right]_{\theta_{i}}^{\theta_{e}}
\end{aligned}
$$

Integration of $\left(\mathrm{t}_{3}\right)$

$$
\begin{aligned}
& \int_{\theta_{i}}^{\theta_{e}} t_{3} d X=\frac{X}{m} \ln (m-X) d X=\frac{1}{m} \int_{\theta_{i}}^{\theta_{e}} X \ln (m-X) d X \\
& =\frac{1}{m} \int_{\theta_{i}}^{\theta_{e}}[(m-X) \ln (m-X)-m \ln (m-x)] d X(m-x) \\
& =\frac{1}{m} \int_{\theta_{i}}^{\theta_{e}}[(m-X) \ln (m-X)] d(m-X) \\
& -\int_{\theta_{i}}^{\theta_{e}} \ln (m-X) d(m-X) \\
& =\left[\frac{1}{m} \frac{(m-X)^{2}}{2}\left\{\ln (m-X)-\frac{1}{2}\right\}-(m-X)\{\ln (m-X)-1\}\right]_{\theta_{i}}^{\theta_{e}} \\
& \operatorname{Re}-\text { arranging: } \\
& =\left[\left\{\frac{-m^{2}+X^{2}}{2 m} \ln (m-X)\right\}-\left\{\frac{-3 m^{2}+2 m X+X^{2}}{4 m}\right\}\right]_{\theta_{i}}^{\theta_{e}} \\
& \text { Then: } \\
& \theta_{e} \\
& \int_{\theta_{i}}^{t_{3}} d X=\left[\left\{\frac{X^{2}-m^{2}}{2 m} \ln (m-X)\right\}-\left\{\frac{X^{2}+2 m X-3 m^{2}}{4 m}\right\}\right]_{\theta_{i}}^{\theta_{e}}
\end{aligned}
$$

Integration of $\left(\mathrm{t}_{4}\right)$ :

It could be done as in (t3) or directly you get the integration after changing the sign of $(\mathrm{X})$ to be:

$$
\int_{\theta_{i}}^{\theta_{e}} t_{4} d X=\left[\left\{\frac{X^{2}-m^{2}}{2 m} \ln (m+X)\right\}-\left\{\frac{X^{2}-2 m X-3 m^{2}}{4 m}\right\}\right]_{\theta_{i}}^{\theta_{e}}
$$

Simplifying:

$$
\int_{\theta_{i}}^{\theta_{e}} t_{3} d X-\int_{\theta_{i}}^{\theta_{e}} t_{4} d X=\left[\left(\frac{m^{2}-X^{2}}{2 m}\right) \ln \frac{(m+X)}{(m-X)}-X\right]_{\theta_{i}}^{\theta_{e}}
$$

And:

$$
\begin{aligned}
& \int_{\theta_{1}}^{\theta_{e}} t_{1} d X-\int_{\theta_{\theta_{1}}}^{\theta_{e}} t_{2} d X=\frac{\left(1-X^{2}\right)}{2}\left[\frac{3-X}{2(1-X)}-\ln (1+X)\right]_{\theta_{1}}^{\theta_{e}} \\
& -\frac{\left(1-X^{2}\right)}{2}\left[\frac{3+X}{2(1+X)}-\ln (1-X)\right]_{\theta_{i}}^{\theta_{e}} \\
& =\left[X+\frac{\left(1-X^{2}\right)}{2} \ln \frac{(1-X)}{(1+X)}\right]_{\theta_{i}}^{\theta_{e}}
\end{aligned}
$$

Then:

$$
\begin{aligned}
& \int_{\theta_{i}}^{\theta_{e}} t_{1} d X-\int_{\theta_{i}}^{\theta_{e}} t_{2} d X=\left[X+\frac{\left(1-X^{2}\right)}{2} \ln \frac{(1-X)}{(1+X)}\right]_{\theta_{i}}^{\theta_{e}} \\
& \text { Then: } \\
& \int_{\theta_{e}}^{\theta_{i}} t_{1}-t_{2}+t_{3}-t_{4} d X= \\
& =\left[X+\frac{\left(1-X^{2}\right)}{2} \ln \frac{(1-X)}{(1+X)}+\left(\frac{m^{2}-X^{2}}{2 m}\right) \ln \frac{(m+X)}{(m-X)}-X\right]_{\theta_{i}}^{\theta_{e}} \\
& =\left[\frac{\left(1-X^{2}\right)}{2} \ln \frac{(1-X)}{(1+X)}-\left(\frac{m^{2}-X^{2}}{2 m}\right) \ln \frac{(m-X)}{(m+X)}\right]_{\theta_{i}}^{\theta_{e}}
\end{aligned}
$$

Then

$$
\mathrm{a}_{2}=\frac{\mathrm{K}_{\mathrm{v}} \mathrm{A}}{4 \mathrm{~b}^{2}}\left[\frac{\left(\cos ^{2} \theta\right)}{2} \ln \frac{(1-\sin \theta)}{(1+\sin \theta)}-\left(\frac{\mathrm{b}^{2}+\cos ^{2} \theta}{2 \sqrt{\mathrm{b}^{2}}+1}\right) \ln \frac{\left(\sqrt{\mathrm{b}^{2}+1}-\sin \theta\right)}{\left(\sqrt{\mathrm{b}^{2}+1}+\sin \theta\right)}\right]_{\theta_{\mathrm{e}}}^{\theta_{\mathrm{e}}}
$$

Hence:

$$
\begin{gathered}
\mathrm{W}=\sin ^{2} \theta+2 \mathrm{~F} \\
\mathrm{~F}=\mathrm{a}_{1}-\mathrm{a}_{2} \\
\mathrm{a}_{1}=\mathrm{A}\left[\frac{\mathrm{b}^{2}+\cos ^{2} \theta}{4 \mathrm{~b}^{2}\left(\mathrm{~b}^{2}+1\right)} \ln \left(\mathrm{b}^{2}+\cos ^{2} \theta\right)-\frac{\sin ^{2} \theta}{2\left(\mathrm{~b}^{2}+1\right)} \ln (\sin \theta)-\frac{\cos ^{2} \theta}{2 \mathrm{~b}^{2}} \ln (\cos \theta)\right]_{\theta_{\mathrm{e}}}^{\theta_{i}} \\
+\frac{\mathrm{S}}{2}\left[\cos ^{4} \theta\right]_{\theta_{\mathrm{i}}}^{\theta_{\mathrm{e}}}-\mathrm{B}\left[\cos ^{2} \theta\right]_{\theta_{\mathrm{i}}}^{\theta_{\mathrm{e}}} \\
\mathrm{a}_{2}=\frac{\mathrm{K}_{\mathrm{v}} \mathrm{A}}{4 \mathrm{~b}^{2}}\left[\frac{\left(\cos ^{2} \theta\right)}{2} \ln \frac{(1-\sin \theta)}{(1+\sin \theta)}-\left(\frac{\mathrm{b}^{2}+\cos ^{2} \theta}{2 \sqrt{\mathrm{b}^{2}}+1}\right) \ln \frac{\left(\sqrt{\mathrm{b}^{2}+1}-\sin \theta\right)}{\left(\sqrt{\mathrm{b}^{2}+1}+\sin \theta\right)}\right]_{\theta_{\mathrm{e}}}^{\theta_{\mathrm{e}}}
\end{gathered}
$$

\section{A3- The Temperature Gradient Equation}

Due to the human printing error appeared in the equation form in references $\left[\begin{array}{l}4 \& 5 \\ \&\end{array}\right]$, the author had to re-derive the equation and he is sure that the equation form in reference [4] is the correct one. So, this form will be adopted after replacing the parameter (S) in this form with that of references [1-3] to be matching with the author's previous studies.

$$
\begin{aligned}
& \frac{\mathrm{dT}}{\mathrm{d} \theta}=\left(\frac{\mathrm{p}_{1}}{\rho \mathrm{c}_{\mathrm{v}}}\right)\left[\left(\frac{\mathrm{dP}}{\mathrm{d} \theta}\right)^{2}-2 \mathrm{~S} \sin (2 \theta)\left(\frac{\mathrm{dP}}{\mathrm{d} \theta}\right)+\frac{(\mathrm{S} \sin 2 \theta)^{2}}{0.84}\right. \\
& \left.+12\left(\frac{\mu \Omega \mathrm{R}^{2} \sin \theta}{\mathrm{p}_{1} \mathrm{~h}^{2}}\right)^{2}\right]\left(\mathrm{S} \sin 2 \theta-\frac{\mathrm{dP}}{\mathrm{d} \theta}\right)^{-1} \quad \mathrm{Ref} .[
\end{aligned}
$$




$$
\begin{aligned}
& \frac{d T}{d \theta}=\left[\left(\frac{d P}{d \theta}\right)^{2}+2 S \sin (2 \theta)\left(\frac{d P}{d \theta}\right)+\left(\frac{S \sin 2 \theta}{0.84}\right)^{2}\right. \\
& \left.+12\left(\frac{\mu \Omega R^{2} \sin \theta}{p_{1} h^{2}}\right)^{2}\right]\left(S \sin 2 \theta-\frac{d P}{d \theta}\right)^{-1}
\end{aligned}
$$

Where:

$$
\mathrm{S}=\frac{0.15 \rho \Omega^{2} \mathrm{R}^{2}}{\mathrm{p}_{1}}
$$

\section{A4-The integration of the frictional factor equation:}

$$
\begin{gathered}
M=\int_{\theta_{i}}^{\theta_{c}} \frac{\left(\cos ^{2} \theta+\sigma^{2}\right)\left(1-K_{V} \sin \theta\right)\left(\cos ^{2} \theta-1\right)}{\cos ^{3} \theta} d(\cos \theta) \\
M=\int_{\theta_{i}}^{\theta_{c}} X d(\cos \theta) \\
X=\frac{\left(\cos ^{2} \theta+\sigma^{2}\right)\left(1-K_{V} \sin \theta\right)\left(\cos ^{2} \theta-1\right)}{\cos ^{3} \theta}
\end{gathered}
$$

Re-arranging:

$$
\begin{gathered}
X=\left[\frac{\cos ^{4} \theta+\left(\sigma^{2}-1\right) \cos ^{2} \theta-\sigma^{2}}{\cos ^{3} \theta}\right]- \\
{\left[\frac{K \sin \theta\left\{\cos ^{4} \theta+\left(\sigma^{2}-1\right) \cos ^{2} \theta-\sigma^{2}\right\}}{\cos ^{3} \theta}\right]} \\
X=\text { term }(1)-\operatorname{term}(2)
\end{gathered}
$$

Integration of term (1)

It could be found in Yacout [1] as:

$$
I_{1}=\left[\frac{\cos ^{2} \theta}{2}+\left(\sigma^{2}-1\right) \ln (\cos \theta)+-\frac{\sigma^{2}}{2 \cos ^{2} \theta}\right]_{\theta_{\mathrm{i}}}^{\theta_{\mathrm{e}}}
$$

Integration of term (2)

$$
\begin{aligned}
& \text { term }(2)=\frac{\left.K_{\mathrm{v}} \sin \theta\left\{\cos ^{4} \theta+\left(\sigma^{2}-1\right) \cos ^{2} \theta-\sigma^{2}\right)\right\}}{\cos ^{3} \theta} \\
& =K_{\mathrm{v}} \sin \theta \cos \theta+\mathrm{K}_{\mathrm{v}}\left(\sigma^{2}-1\right)\left(\frac{\sin \theta}{\cos \theta}\right)-\mathrm{K}_{\mathrm{v}} \sigma^{2}\left(\frac{\sin \theta}{\cos ^{3} \theta}\right)
\end{aligned}
$$

Integration of term (2):

$$
\mathrm{I}_{2}=\mathrm{K}_{\mathrm{v}} \mathrm{a}_{1}+\mathrm{K}_{\mathrm{v}}\left(\sigma^{2}-1\right) \mathrm{a}_{2}-\mathrm{K}_{\mathrm{v}} \sigma^{2} \mathrm{a}_{3}
$$

Where:

$$
\begin{aligned}
& \mathrm{a}_{1}=\int_{\theta_{\mathrm{i}}}^{\theta_{\mathrm{e}}} \sin \theta \cos \theta d(\cos \theta) \\
& \mathrm{a}_{2}=\int_{\theta_{\mathrm{i}}}^{\theta_{\mathrm{e}}}\left(\frac{\sin \theta}{\cos \theta}\right) \mathrm{d}(\cos \theta) \\
& \mathrm{a}_{3}=\int_{\theta_{\mathrm{i}}}^{\theta_{\mathrm{e}}}\left(\frac{\sin \theta}{\cos ^{3} \theta}\right) \mathrm{d}(\cos \theta)
\end{aligned}
$$

Integration of each part:

$$
\mathrm{a}_{1}=\int_{\theta_{\mathrm{i}}}^{\theta_{\mathrm{c}}} \sin \theta \cos \theta \mathrm{d}(\cos \theta)
$$

$$
\begin{gathered}
a_{1}=-\int_{\theta_{i}}^{\theta_{e}} \sin ^{2} \theta \cos \theta d \theta=-\int_{\theta_{i}}^{\theta_{e}} \sin ^{2} \theta d(\sin \theta) \\
a_{1}=-\left[\frac{\sin ^{3} \theta}{3}\right]_{\theta_{i}}^{\theta_{e}}
\end{gathered}
$$

$$
\begin{aligned}
& a_{2}=\int_{\theta_{i}}^{\theta_{e}}\left(\frac{\sin \theta}{\cos \theta}\right) d(\cos \theta)=-\int_{\theta_{i}}^{\theta_{e}}\left(\frac{\sin ^{2} \theta}{\cos \theta}\right) d \theta \\
& =-\int_{\theta_{\mathrm{i}}}^{\theta_{\mathrm{e}}} \frac{\left(1-\cos ^{2} \theta\right)}{\cos \theta} \mathrm{d} \theta \\
& \mathrm{a}_{2}=\int_{\theta_{\mathrm{i}}}^{\theta_{\mathrm{e}}} \cos \theta \mathrm{d} \theta-\int_{\theta_{\mathrm{i}}}^{\theta_{\mathrm{e}}} \frac{1}{\cos \theta} \mathrm{d} \theta \\
& =[\sin \theta]_{\theta_{\mathrm{i}}}^{\theta_{\mathrm{e}}}-\left[\ln \left(\tan \theta+\frac{1}{\cos \theta}\right)\right]_{\theta_{\mathrm{i}}}^{\theta_{\mathrm{e}}} \\
& \mathrm{a}_{2}=[\sin \theta-\ln (\tan \theta+\sec \theta)]_{\theta_{\mathrm{i}}}^{\theta_{\mathrm{e}}} \\
& \mathrm{a}_{3}=\int_{\theta_{\mathrm{i}}}^{\theta_{\mathrm{e}}}\left(\frac{\sin \theta}{\cos ^{3} \theta}\right) \mathrm{d}(\cos \theta) \\
& =-\int_{\theta_{\mathrm{i}}}^{\theta_{\mathrm{e}}}\left(\frac{\sin ^{2} \theta}{\cos ^{3} \theta}\right) \mathrm{d} \theta=-\int_{\theta_{\mathrm{i}}}^{\theta_{\mathrm{e}}}\left(\frac{1-\cos ^{2} \theta}{\cos ^{3} \theta}\right) \mathrm{d} \theta \\
& =\int_{\theta_{\mathrm{i}}}^{\theta_{\mathrm{e}}}\left(\frac{1}{\cos \theta}-\frac{1}{\cos ^{3} \theta}\right) \mathrm{d} \theta \\
& =\int_{\theta_{\mathrm{i}}}^{\theta_{\mathrm{e}}}\left(\frac{1}{\cos \theta}\right) \mathrm{d} \theta-\int_{\theta_{\mathrm{i}}}^{\theta_{\mathrm{e}}}\left(\frac{1}{\cos ^{3} \theta}\right) \mathrm{d} \theta
\end{aligned}
$$

Then:

$$
\int_{\theta_{\mathrm{i}}}^{\theta_{\mathrm{e}}}\left(\frac{1}{\cos \theta}\right) d \theta=\left[\ln \left(\tan \theta+\frac{1}{\cos \theta}\right)\right]_{\theta_{\mathrm{i}}}^{\theta_{e}}
$$

And:

$$
\begin{aligned}
& \int_{\theta_{\mathrm{i}}}^{\theta_{\mathrm{e}}}\left(\frac{1}{\cos ^{3} \theta}\right) \mathrm{d} \theta=\int_{\theta_{\mathrm{i}}}^{\theta_{e}}\left(\operatorname{ecs}^{3} \theta\right) \mathrm{d} \theta \\
& =\frac{1}{2}[\sec \theta \tan \theta+\ln (\sec \theta+\tan \theta)]_{\theta_{\mathrm{i}}}^{\theta_{e}}
\end{aligned}
$$

Then:

$$
\begin{aligned}
& \mathrm{a}_{3}=[\ln (\sec \theta+\tan \theta)]_{\theta_{\mathrm{i}}}^{\theta_{\mathrm{e}}}- \\
& \frac{1}{2}[\sec \theta \tan \theta+\ln (\sec \theta+\tan \theta)]_{\theta_{\mathrm{i}}}^{\theta_{\mathrm{e}}} \\
& =\frac{1}{2}[\ln (\sec \theta+\tan \theta)-\sec \theta \tan \theta]_{\theta_{\mathrm{i}}}^{\theta_{\mathrm{e}}}
\end{aligned}
$$

Then:

$$
\mathrm{I}_{2}=\mathrm{K}_{\mathrm{v}} \mathrm{a}_{1}+\mathrm{K}_{\mathrm{v}}\left(\sigma^{2}-1\right) \mathrm{a}_{2}-\mathrm{K}_{\mathrm{v}} \sigma^{2} \mathrm{a}_{3}
$$




$$
\begin{gathered}
\mathrm{I}_{2}=-\mathrm{K}_{\mathrm{v}}\left[\sin ^{3} \theta / 3\right]_{\theta_{\mathrm{i}}}^{\theta_{\mathrm{e}}}+ \\
\mathrm{K}_{\mathrm{v}}\left(\sigma^{2}-1\right)[\sin \theta-\ln (\tan \theta+\sec \theta)]_{\theta_{\mathrm{i}}}^{\theta_{\mathrm{e}}}- \\
\frac{1}{2} \mathrm{~K}_{\mathrm{v}} \sigma^{2}[\ln (\sec \theta+\tan \theta)-\sec \theta \tan \theta]_{\theta_{\mathrm{i}}}^{\theta_{\mathrm{e}}} \\
\mathrm{I}_{2}=\mathrm{K}_{\mathrm{v}}\left[\left(\sigma^{2}-1\right)\{\sin \theta-\ln (\tan \theta+\sec \theta)\}-\right. \\
\left.\frac{\sigma^{2}}{2}\{\ln (\sec \theta+\tan \theta)-\sec \theta \tan \theta\}-\frac{\sin ^{3} \theta}{3}\right]_{\theta_{\mathrm{i}}}^{\theta_{\mathrm{e}}}
\end{gathered}
$$

The whole integration:

$$
\begin{gathered}
M=I_{1}-I_{2} \\
M=\left[\frac{\cos ^{2} \theta}{2}+\left(\sigma^{2}-1\right) \ln (\cos \theta)+-\frac{\sigma^{2}}{2 \cos ^{2} \theta}\right]_{\theta_{\mathrm{i}}}^{\theta_{\mathrm{e}}}- \\
\mathrm{K}_{\mathrm{v}}\left[\left(\sigma^{2}-1\right)\{\sin \theta-\ln (\tan \theta+\sec \theta)\}-\right. \\
\left.\frac{\sigma^{2}}{2}\{\ln (\sec \theta+\tan \theta)-\sec \theta \tan \theta\}-\frac{\sin ^{3} \theta}{3}\right]_{\theta_{\mathrm{i}}}^{\theta_{\mathrm{e}}}
\end{gathered}
$$

\section{A5- The adopted form of the Temperature equation}

$$
\begin{aligned}
& \frac{\mathrm{dT}}{\mathrm{d} \theta}=\left(\frac{\mathrm{p}_{1}}{\rho \mathrm{c}_{\mathrm{v}}}\right)\left[\left(\frac{\mathrm{dP}}{\mathrm{d} \theta}\right)^{2}-4 \mathrm{~S} \sin (2 \theta)\left(\frac{\mathrm{dP}}{\mathrm{d} \theta}\right)+\frac{(\mathrm{S} \sin 2 \theta)^{2}}{0.21}\right. \\
& \left.+12\left(\frac{\mu \Omega \mathrm{R}^{2} \sin \theta}{\mathrm{p}_{1} \mathrm{~h}^{2}}\right)^{2}\right]\left(2 \mathrm{~S} \sin 2 \theta-\frac{\mathrm{dP}}{\mathrm{d} \theta}\right)^{-1}
\end{aligned}
$$

Where:

$$
\mathrm{S}=3 / 40\left(\rho \Omega^{2} \mathrm{R}^{2} / \mathrm{p}_{1}\right)
$$

\section{A6- The adopted form of the viscosity equation}

Two forms of the viscosity variation equation have been applied in previous studies [3,4 and 5], a comparison between both is shown in figure $\left(A_{1}\right)$.

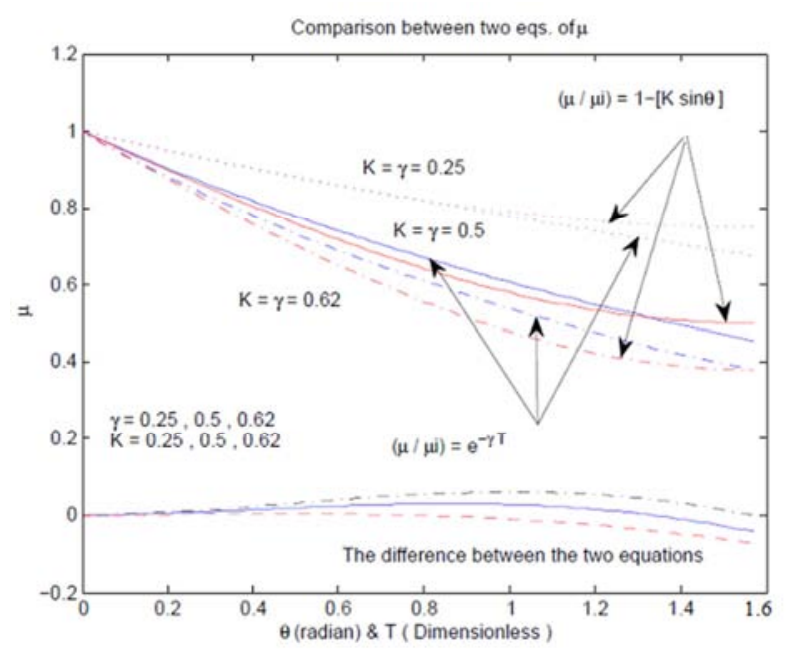

Figure 1A. Comparison between the two equations of the viscosity variation.
The adopted equation in this study is:

$$
\mu=\mu_{\mathrm{i}}\left(1-\mathrm{K}_{\mathrm{v}} \sin \theta\right) \quad \operatorname{Ref} .[4]
$$

\section{References}

[1] Ahmad W. Yacout, Ashraf S. Ismaeel, Sadek Z. Kassab, The combined effects of the centripetal inertia and the surface roughness on the hydrostatic thrust spherical bearing performance, Tribolgy International Journal 2007, Vol.40, No. $3,522-532$.

[2] Dowson D. and Taylor M. Fluid inertia effect in spherical hydrostatic thrust bearings. ASLE Trans. 1967, 10, 316- 324.

[3] Dowson D. and Taylor M. A Re- Examination of hydrosphere performance, ASLE Trans. 1967, 10, 325- 333.

[4] Khalil M. F. Theoretical and experimental analysis of externally pressurized axi-symmetrical bearings, $\mathrm{PhD}$ thesis, Alexandria University, Alex. Egypt, 1974.

[5] Essam Salem and Farid Khalil, Variable Viscosity effects in Externally Pressurized Spherical Oil Bearings, Journal of Wear 1978, 50, 221-235.

[6] Rowe W. B. and Stout K. J. Design data and a manufacturing technique for spherical hydrostatic bearings in machine tool applications, Int. J. Mach. Tool Des. Res. 1971, Vol. 11, 293307.

[7] Keith Brockwell, Scan Decamillo and Waldemar Dmochowski, Measured temperature characteristics of $152 \mathrm{~mm}$ diameter pivoted shoe journal bearings with flooded lubrication, Tribology Transaction 2001, vol. 44, No. 4, 543-550.

[8] Minhui He, Cloud C. Hunter and James M. Byrne, Fundamentals of Fluid Film Journal Bearing Operation and Modeling, Proceedings of the thirty fourth Turbo-machinery Symposium 2005.

[9] Srinivasan V. Analysis of Static and Dynamic Load on the Hydrostatic Bearing with Variable Viscosity Affected by the Environmental Temperature, Journal of Environmental Research and Development 2012, Vol.7, No. 1A, 346-353.

[10] Shigang Wang, Xianfeng Du, Mingzhu Li, Zhongliang Cao, Jianjia Wang, Analysis of temperature effect on the lubricating state of hydrostatic bearing, Journal of Theoretical and Applied Information Technology 2013, Vol. 48, No. 2, 817821.

[11] Xibing Li, Xun Wang, Ming Li, Yunshi Ma and Ying Huang, The Research Status and Progress of Heavy/Large Hydrostatic Thrust Bearing, Hidawi Publishing Corporation, Advances in Mechanical Engineering, volume 2014, Article ID: 982584. http://dx.doi.org/10.1155/2014/982584 